\title{
Kemampuan Avicennia alba untuk Menurunkan Konsentrasi Tembaga (Cu) di Muara Sungai Wonorejo, Surabaya
}

\author{
Bintang Respati Dwi Harnani dan Harmin Sulistiyaning Titah \\ Departemen Teknik Lingkungan, Fakultas Teknik Sipil dan Perencanaan, Institut Teknologi Sepuluh Nopember
}

(ITS)

o-mail. harmin st@its as id

\begin{abstract}
Abstrak-Peningkatan jumlah industri dan pertumbuhan penduduk menjadi sumber pencemar utama di wilayah muara sungai. Muara sungai merupakan tempat penampungan limbah terakhir sebelum menuju laut lepas. Sungai Wonorejo merupakan satu dari tujuh sungai yang bermuara ke Pantai Timur Surabaya yang berpotensi mengandung banyak logam berat. Pada penelitian ini diukur konsentrasi $\mathrm{Cu}$ yang terdapat pada sedimen dan akar mangrove Avicennia alba di muara Sungai Wonorejo. Selanjutnya akan dihitung nilai Bioconsentration Factor (BCF) dari mangrove $A$. alba yang ada di muara sungai Wonorejo. Metode yang digunakan pada penelitian ini adalah metode transek untuk menentukan titik pengambilan sampel akar mangrove A. alba dan sedimennya. Akar mangrove dan sedimen diekstrak menggunakan metode destruksi basah dengan Aqua Regia. Sampel yang didapatkan kemudian dianalisis menggunakan Atomic Absorbtion Spectrofotometer (AAS. Parameter pendukung yang diukur meliputi suhu menggunakan termometer, salinitas menggunakan salinometer dan pH menggunakan pH meter untuk tanah. Konsentrasi rata-rata $\mathrm{Cu}$ yang ada di sedimen muara Sungai Wonorejo pada sedimen disekitar A. alba yaitu $24,85 \mathrm{mg} / \mathrm{kg}$, Konsentrasi Cu pada mangrove $A$. alba sebesar $51,5 \mathrm{mg} / \mathrm{kg}$ Nilai BCF pada $A$. alba adalah 1, 13- 2, 89. Hal ini menunjukan bahwa $A$. alba merupakan tumbuhan hiperakumulator logam berat $\mathrm{Cu}$.
\end{abstract}

Kata Kunci-A. alba, Cu, Mangrove, Muara, Wonorejo.

\section{PENDAHULUAN}

$\mathrm{P}$ ENCEMARAN laut dapat dibedakan menjadi pencemaran daerah pantai, estuaria dan lepas pantai. Pencemaran pantai dapat disebabkan karena limbah industri, sampah, sedimentasu dan kegiatan pertanian [1]. Sungai Wonorejo merupakan sungai yang bermuara di Pantai Timur Surabaya. Sungai Wonorejo merupakan terusan dari Kali Jagir yang dalam aliranya membawa limbah industri.

Daerah Pantai Timur Surabaya mempunyai ekosistem hutan mangrove yang tergolong rapat. Daerah ini mempunyai kadar salinitas yang tinggi dan berada pada ketinggian 0-3 m diatas permukaan air laut [2]. Kandungan $\mathrm{Cu}$ yang terukur pada muara Sungai Wonorejo pada tahun 2009 sekitar 3,186 mg/L.

Muara sungai Wonorejo memiliki ketebalan hutan mangrove sekitar 10 - 20 meter [3]. Kawasan muara sungai Wonorejo memiliki jenis mangrove yang beragam. Jenis mangrove yang ada di sekitar Sungai Wonorejo antara lain jenis Avicennia marina, Avicennia alba, Excoecaria agalocha,
Avincinnia officinallis [4]. Mangrove memiliki toleransi yang tinggi terhadap logam berat. Akumulasi logam berat terjadi pada bagian akar, batang dan daun mangrove [5].

Remediasi logam berat menggunakan tumbuhan merupakan salah satu solusi dengan biaya yang murah, dan hemat tenaga tetapi membutuhkan waktu yang lama [6]. Muara sungai Wonerojo merupakan tempat yang berbatasan dengan laut sehingga mempunyai tingkat salinitas yang relative tinggi sehingga diperlukan tumbuhan yang cocok untuk proses remediasi. Mangrove cocok diterapkan di wilayah tersebut karena dapat hidup diwilayah salinitas tinggi dan merupakan tumbuhan yang paling dominan tumbuh di sekitar muara sungai [7].

Pada penelitian ini akan diukur berapa kandungan $\mathrm{Cu}$ yang terdapat sedimen muara Sungai Wonorejo dan bagian akar mangrove $A$. alba yang ada di sekitar muara Sungai Wonorejo. Pengukuran ini dilakukan untuk mengetahui seberapa besar mangrove dapat mengakumulasi logam berat $\mathrm{Cu}$. Pemilihan jenis mangrove berdasarkan jumlah populasi dominan yang ada di sekitar muara sungai Wonorejo.

\section{METODE PENELITIAN}

\section{A. Persiapan Sampling}

Langkah pertama yang dilakukan dalam penelitian ini adalah melakukan survey lapangan untuk menentukan tempat pengambilan sampling. Setelah tempat pengambilan sampling ditetapkan dilakukan pemilihan jenis mangrove jenis $A$. alba yang akan diambil sampel akar. Plotting dilakukan untuk menentukan titik pengambilan sampel yang diambil nantinya. Titik pengambilan sampel dipilih berdasarkan persebaran mangrove A. alba yang ada di muara Sungai Wonorejo. Sampel pohon mangrove yang dipilih harus memiliki diameter lebih dari $5 \mathrm{~cm}$ hal ini berkaitan dengan umur mangrove dan kemampuan mangrove dalam menyerap logam berat. Mangrove yang memiliki diameter di atas $5 \mathrm{~cm}$ memiliki sistem perakaran yang kuat. Sistem perakaran yang kuat dapat menunjang kemampuan penyerapan logam berat [8]. Hal lain yang diperhatikan dalam plotting yaitu tentang titik pengambilan sampel harus selalu terkena pasang surut air laut. Plotting dilakukan dengan pada tanggal 2 Maret 2017 pukul 13.00 WIB saat air laut surut. Pada saat plotting dilakukan juga identifikasi mangrove. 


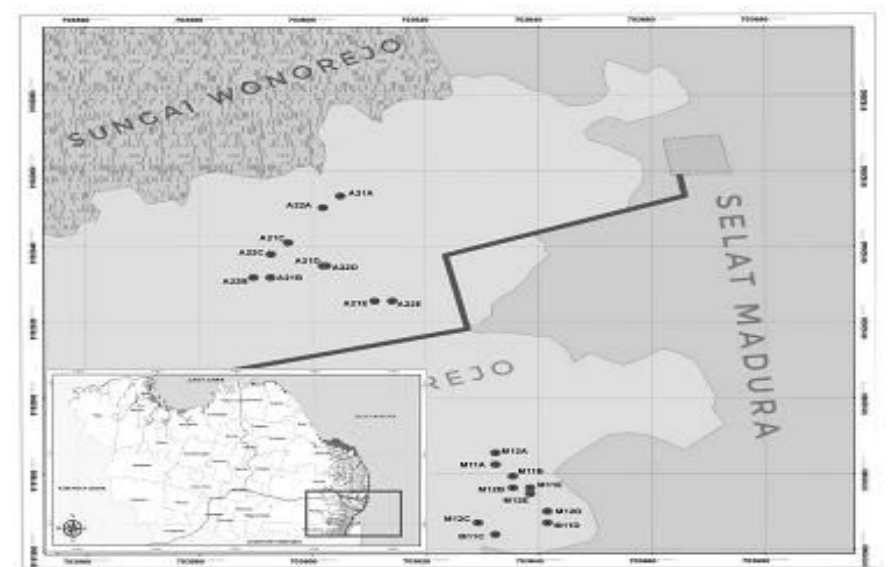

Gambar 1. Persebaran Titik sampling.

Identifikasi mangrove meliputi bentuk warna daun, batang, dan bunga jika ada. Peta pengambilan titik sampling dapat dilihat pada Gambar 1. Mangrove A. alba terletak dibagian atas pada peta dengan simbol A21A-A22E. Pada muara Sungai Wonorejo letak A. alba berbatasan langsung dengan Selat Madura. A. alba merupakan salah satu mangrove pionir yang berfungsi untuk memecah gelombang laut dan melindungi mangrove-mangrove yang ada dibelakangnya.

Tabel 1.

Katagori Nilai BCF [9][10]

\begin{tabular}{ll}
\multicolumn{2}{c}{ Katagori Nilai BCF [9][10] } \\
\hline \hline \multicolumn{1}{c}{ Katagori } & \multicolumn{1}{c}{ Rentang } \\
\hline Tanaman akumulator tinggi & $1-10$ \\
Tanaman akumulator sedang & $0,1-1$ \\
Tanman akumulator rendah & $0,01-0,1$ \\
Tanaman bukan akumulator & $<0,01$ \\
\hline \hline
\end{tabular}

\section{A. Pengambilan Sampel}

Pengambilan sampel dilakukan dengan mencatat titik koordinat mangrove menggunakan GPS. GPS yang digunakan dalam percobaan ini adalah tipe Garmin GPSmap 765Sx. Sampel yang diambil berjumlah 20 yang terdiri dari 10 sampel sedimen disekitar A. alba dan 10 sampel akar A. alba.

Pengambilan sampel sedimen dilakukan secara random sampling dengan kedalaman 0-30 $\mathrm{cm}$ menggunakan bor dan berjarak sekitar $30 \mathrm{~cm}$ dari pohon mangrove yang diambil sampel akarnya. Kandungan $\mathrm{Cu}$ pada sedimen semakin dalam akan semakin tinggi, terutama pada kedalaman $25 \mathrm{~cm}$ [11]. Sedimen yang dibawa aliran sungai semakin lama semakin banyak dan mengendap di muara sungai hal ini dikarenakan prosses sedimentasi. Sampel sedimen dimasukkan ke dalam plastik kemudian diberi label dan disimpan dalam coolbox untuk dibawa ke laboratorium. Pada saat pengambilan sampel sedimen dilakukan pegukuran suhu sedimen yang diambil menggunakan thermometer dan $\mathrm{pH}$ sedimen mengunakan soil meter

Sampel sedimen maupun akar amangrove A. alba yang sudah diambil kemudian dilakukan proses destruksi. Proses destruksi menggunakan metode destruksi basah dengan larutan Aqua Regia. Aqua regia merupakan percampuran $\mathrm{HCl}$ dan $\mathrm{HNO}_{3}$ dengan perbandingan 1:3. Sampel dikeringkan didalam oven selama 24 jam kemudian diambil 1 gram untuk ditambahkan $28 \mathrm{ml}$ aqua regia. Sampel didiamkan selama 24 jam setelah itu dipanaskan dengan kompor listrik hingga

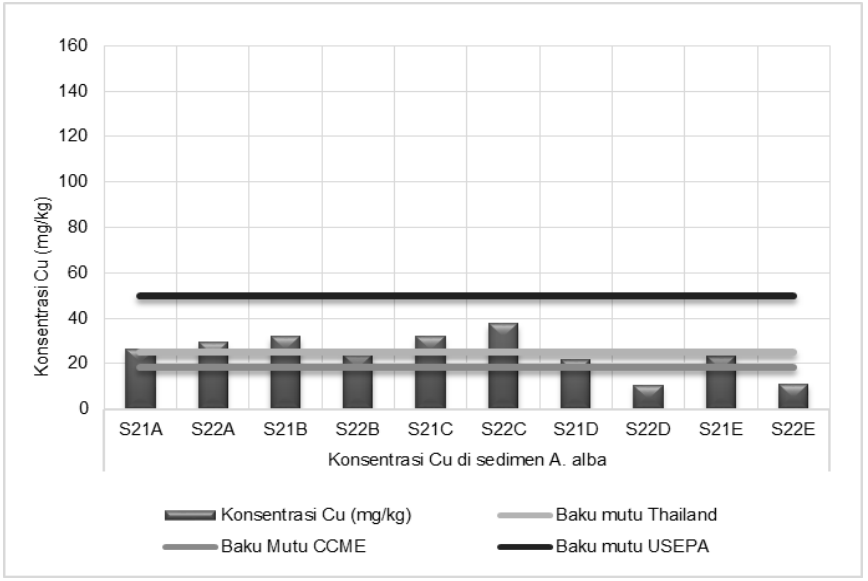

Gambar 2. Konsentrasi Cu Sedimen.

volume sampel sekitar $5 \mathrm{ml}$. Setelah itu ditambahkan $20 \mathrm{ml}$ aquades dan disaring dengan kertas saring. Hasil saringan diencerkan sampai $50 \mathrm{ml}$ kemudian sampel siap diukur dengan AAS [12].

\section{HASIL DAN PEMBAHASAN}

\section{A. Konsentrasi $\mathrm{Cu}$ di Sedimen}

Rata-rata konsentrasi $\mathrm{Cu}$ di sedimen sekitar A. alba sebesar $44,8 \mathrm{mg} / \mathrm{kg}$. Indonesia belum memiliki baku mutu untuk sedimen kawasan pesisir. Pada Gambar 2 konsentrasi $\mathrm{Cu}$ di sedimen sangat berfluktuatif.. Di sekitar A. alba lebih sering terjadi turbulensi arus air laut. Kawasan A. alba merupakan tempat bertemunya air tawar dari sungai dan air laut yang mengakibatkan pengendapan logam berat sulit terjadi. Konsentrasi logam berat di wilayah tersebut akan cenderung berubah-ubah. Indonesia hanya memiliki baku mutu tentang air laut yang tertulis dalam Keputusan Menteri Lingkungan Hidup Nomor 51 tahun 2004 yang dibagi menjadi 3 katagori yaitu untuk kawasan pelabuhan, wisata bahari dan biota laut. Oleh karena itu, pada penelitian ini baku mutu yang digunakan mengacu pada berbagai negara yang sudah mempunyai baku mutu sedimen kawasan pesisir, diantaranya yaitu Canadian council of Ministers for Environment (CCME) dari Kanada, Pollution Control Department of Thailand, dan USA.

Baku mutu untuk CCME ditetapkan sebesar $18,7 \mathrm{mg} / \mathrm{kg}$, baku mutu dari Thailand untuk sedimen yaitu $25 \mathrm{mg} / \mathrm{kg}$ dan dari USEPA digunakan $50 \mathrm{mg} / \mathrm{kg}$ untuk sedimen tercemar berat.

Tingginya konsentrasi $\mathrm{Cu}$ yang ada di sedimen muara Sungai Wonorejo berasal dari polutan logam berat yang terbawa oleh aliran sungai. Sumber polutan yang terbanyak adalah limbah domestik dan industri yang terdapat di sepanjang aliran Sungai Wonorejo. Disamping itu, limbah dari pertanian yang mengandung insektisida, cat kapal dan juga aktifitas pengisian bahan bakar dari kapal nelayan menambah polutan yang ada di muara sungai [13].

Distribusi logam berat $\mathrm{Cu}$ pada sedimen juga dipengaruhi oleh tekstur sedimen. Sedimen di muara pantai Timur Surabaya didominasi oleh stuktur tanah liat [2]. Sedimen yang didominasi oleh tanah liat mengandung kontaminan logam berat yang lebih tinggi daripada sedimen jenis pasir [14]. 


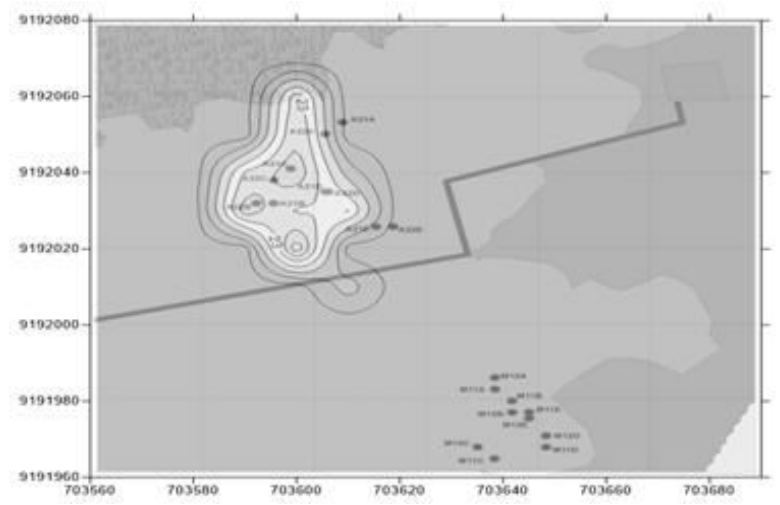

Gambar 3. Persebaran Konsentrasi Cu di Sedimen.

Tanah liat dapat mengikat logam berat $\mathrm{Cu}$ lebih baik dibandingkan tanah jenis pasir atau lumpur.

Hasil penelitian kemudian diplotkan dalam sebuah aplikasi untuk melihat persebaran $\mathrm{Cu}$ di sedimen sekitar A. alba. Dari hasil penelitian didapatkan semakin mendekati muara sungai konsentrasi $\mathrm{Cu}$ disedimen semakin kecil hal ini terjadi karena arus pertemuan antara sungai dan laut cukup besar yang menjadikan $\mathrm{Cu}$ sulit mengendap

\section{A. Konsentrasi Cu di Akar A. alba}

Konsentrasi rata-rata $\mathrm{Cu}$ yang terakumulasi di dalam akar $A$. alba sebesar $51,5 \mathrm{mg} / \mathrm{kg}$. Setiap jenis mangrove mempunyai kemampuan yang berbeda-beda dalam menyerap logam berat. Perbedaan konsentrasi logam berat yang ada pada mangrove berkaitan dengan proses fisiologis mangrove tersebut. Logam berat $\mathrm{Cu}$ dapat diserap oleh mangrove melalui mekanisme absorpsi dan dengan translokasi. $\mathrm{Cu}$ yang masuk ke akar akan disimpan di vakuola dan ditransokasikan ke jaringan lainnya seperti batang dan daun mangrove [15].

Perbedaan penyerapan setiap mangrove dalam mengakumulasikan logam berat berbeda. Faktor yang dapat mempengaruhi mangrove menyerap logam berat antara lain jenis spesiesnya, tingkat pertumbuhannya, faktor non biologi seperti suhu, salinitas, $\mathrm{pH}$, umur tanaman dan musim [16]. Pada musim penghujan konsentrasi $\mathrm{Cu}$ pada sedimen akan semakin rendah jika dibandingkan pada musim kemarau. Pada musim kemarau $\mathrm{pH}$ sedimen semakin asam yang menyebabkan kelarutan $\mathrm{Cu}$ semakin bertambah [17].

Penyerapan logam berat yang dilakukan oleh tumbuhan mangrove dapat melalui sedimen dan kolom air [18]. Logam berat tembaga $(\mathrm{Cu})$ yang diserap tumbuhan harus dalam bentuk ion atau $\mathrm{Cu}^{2+}$. Akar mangrove yang menyarap logam berat akan mendistribusikan kebagian jaringan-jaringan yang lain seperti batang daun, dan buahnya.

Mekanisme akar dalam menyerap logam berat bisa dibagi menjadi 3 bagian:

1. Akar dapat menyerap logam berat jika logam berat dalam bentuk ion terlarut dalam hal ini $\mathrm{Cu}^{2+}$.

2. Logam berat $\mathrm{Cu}$ yang sudah terabsorbsi kemudian ditranslokasikan ke jaringan tumbuhan yang lain. Setelah logam berat menembus endodermis akar, kemudian diedarkan kebagian lain tumbuhan melalui jaringan transportasi (xylem dan floem).

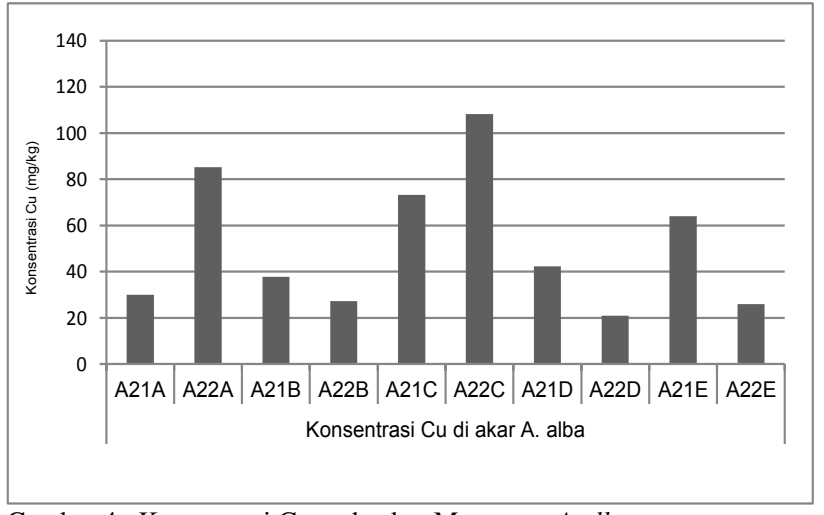

Gambar 4. Konsentrasi Cu pada akar Mangrove A alba.

3. Logam berat yang sudah masuk dalam mangrove kemudian ditempatkan di beberapa sel dan jaringan. Bagian mangrove yang mengakumulasikan logam berat terbanyak adalah akar. Hal ini dikarenakan logam berat yang berlebihan bisa mengganggu metabolisme mangrove itu sendiri [19].

\section{B. Parameter pH, Salinitas, dan Suhu}

Kondisi derajat keasaman $(\mathrm{pH})$ sedimen disekitar A. alba cukup berfluktuatif. Nilai $\mathrm{pH}$ sedimen sekitar $A$. alba berkisar 6 . Baku mutu yang mengatur tentang $\mathrm{pH}$ sedimen di Indonesia belum ada. $\mathrm{pH}$ sedimen yang berkisar 6-7 masih tergolong normal [20]. Kelarutan $\mathrm{Cu}$ akan meningkat tajam jika $\mathrm{pH}$ turun drastis yaitu sekitar 5 [21].

Tinggi rendahnya $\mathrm{pH}$ sedimen dapat mempengaruhi kelarutan logam berat. Semakin rendah $\mathrm{pH}$ akan meningkatkan kelarutan logam berat dan meningkatkan penyerapan logam berat oleh mangrove [7].

Nilai salinitas di sekitar A. alba adalah 1-2 ppt. Penurunan salinitas di sekitar A. alba dikarena letak A. alba yang dekat dengan muara sungai sehingga air tawar dari sungai menurunkan salinitas di sekitar A. alba. Hal yang dapat berpengaruh terhadap perbedaan salinitas adalah penguapan dan curah hujan [22]. Mangrove jenis Avicennia dapat hidup pada kadar salinitas sampai dengan 30 ppt [23]. Kadar salinitas yang terukur masih memenuhi rentang hidup mangrove. Salinitas untuk rentang hidup mangrove adalah sampai dengan 34 ppt [24]. Selain itu, nilai salinitas juga berpengaruh terhadap logam berat $\mathrm{Cu}$ yang ada.

Salinitas di lingkungan perairan dipengaruhi oleh beberapa faktor seperti pola sirkulasi air, penguapan, curah hujan dan aliran sungai. Pada perairan yang dekat dengan muara sungai salinitas sangat dipengaruhi oleh adanya air laut dan air tawar [25].

Pada pengukuran suhu yang dilakukan terhadap sedimen didapatkan hasil suhu pada sedimen di sekitar mangrove jenis A. alba berkisar $28-31^{\circ} \mathrm{C}$. Parameter suhu juga dihubungkan dengan konsentrasi logam berat $\mathrm{Cu}$ yang ada di sedimen. Peningkatan suhu perairan cenderung meningkatkan akumulasi dan toksisitas $\mathrm{Cu}$, hal dikarenakan meningkatnya laju metabolisme dari organisme air [22]. 


\begin{tabular}{rlrrr}
\hline \hline Mangrove & Sampel & $p H$ & Suhu & Salinitas \\
\hline A. alba & S21A & 6.4 & 29 & 1.9 \\
& S22A & 6.6 & 29 & 2.25 \\
& S21B & 6.8 & 28.5 & 2.56 \\
& S22B & 6.8 & 29 & 2.5 \\
& S21C & 6.4 & 29 & 3.31 \\
& S22C & 6.8 & 30 & 3.63 \\
& S21D & 6.4 & 29 & 2.51 \\
& S22D & 6.8 & 29 & 2.46 \\
& S21E & 6.8 & 28.5 & 2.91 \\
& S22E & 6.8 & 29 & 2.7 \\
\hline \hline
\end{tabular}

\section{A. Biokonsentrasi Faktor}

Nilai BCF merupakan ratio kandungan konsentrasi logam berat yang terdapat didalam akar atau daun dengan medianya. Biokonsentrasi faktor diukur untuk mengetahui kemampuan mangrove dalam mengabsorbsi logam berat yang ada di sedimen. Nilai BCF mangrove $A$. alba adalah 1,13-2,89. Dari hasil tersebut nilai BCF dari A. alba rata-rata lebih besar dari 1 (>1). Sehingga dapat disimpulkan bahwa A. alba merupakan tumbuhan yang mempunyai efisiensi tinggi sebagai tumbuhan hiperakumulator logam berat $\mathrm{Cu}$ [26]. Besar kecilnya nilai $\mathrm{BCF}$ dipengaruhi oleh beberapa hal seperti jenis logam berat, organisme yang ada, lama pemaparan dan kondisi perairan [10].

Nilai BCF yang besar juga menunjukan bahwa akumulasi logam berat $\mathrm{Cu}$ relatif besar dari sedimen ke akar mangrove. Konsentrasi nilai $\mathrm{Cu}$ di sedimen dipengaruhi oleh suhu salinitas, $\mathrm{pH}$ dan masukan limbah dari berbagai sumber seperti industri dan limbah domestik.

Penelitian ini membuktikan bahwa rata-rata kandungan akar yang ada pada mangrove $A$. alba lebih besar dari kandungan sedimen yang berada di sekitarnya. konsentrasi logam berat pada jaringan tumbuhan meningkat seiring dengan peningkatan konsentrasi sedimen [27].

\section{KESIMPULAN}

Konsentrasi sedimen rata-rata logam berat $\mathrm{Cu}$ yang terdapat di muara Sungai Wonorejo pada sedimen di sekitar A. alba yaitu 24,85 mg/kg Untuk kandungan konsentrasi Cu pada akar A. alba di muara Sungai Wonorejo sekitar $51,5 \mathrm{mg} / \mathrm{kg}$.

Nilai Bioconsentrasi Factor (BCF) dari mangrove A. alba rata-rata mempunyai nilai sebesar $1,13-2,89$ Nilai $\mathrm{BCF}$ menunjukan kedua mangrove merupakan tumbuhan hiperakumulator terhadap logam berat karena nilai $\mathrm{BCF}$ melebihi 1 sehingga mangrove $A$. alba termasuk tumbuhan hiperakumulator.

\section{DAFTAR PUSTAKA}

[1] A. Taftazani, "Distribusi Konsentrasi Logam Berat Hg Dan Cr Pada Sampel Lingkungan Perairan Surabaya," in Prosiding PPI PDIPTN2, 2007.

[2] Arisandi, "Mangrove Jenis Api-api (Avicennia marina) Alternatif Pengendalian Logam Berat Pesisir,” 2001.

\begin{tabular}{rccrrr}
\multicolumn{6}{c}{ Tabel 3. } \\
\hline \hline No & $\begin{array}{l}\text { Nama Bai BCF } \\
\text { mangrove }\end{array}$ & Simbol & $\begin{array}{l}\text { Sedimen } \\
(\mathrm{mg} / \mathrm{kg})\end{array}$ & $\begin{array}{l}\text { Akar } \\
(\mathrm{mg} / \mathrm{kg})\end{array}$ & $B C F$ \\
\hline 1 & A. alba & A21A & 26.5 & 30 & 1.13 \\
2 & & A22A & 29.5 & 85.25 & 2.89 \\
3 & A21B & 32 & 37.75 & 1.18 \\
4 & A22B & 24 & 27.25 & 1.14 \\
5 & A21C & 32 & 73.25 & 2.29 \\
6 & A22C & 37.5 & 108.25 & 2.89 \\
7 & A21D & 22 & 42.25 & 1.92 \\
8 & A22D & 10.5 & 21 & 2.00 \\
9 & A21E & 23.5 & 64 & 2.72 \\
10 & A22E & 11 & 26 & 2.36 \\
\hline \hline
\end{tabular}

[3] H. Adiwijaya, "Kondisi Mangrove Pantai Timur Surabaya dan Dampaknya Terhadap Lingkungan Hidup," J. Ilm. Tek. Lingkung., 2008.

[4] Badan Lingkungan Hidup Koata Surabaya, "Laporan Pengendalian Kawasan Pesisir dan Laut Tahun 2012," Surabaya, 2012.

[5] G. R. MacFarlane and M. D. Burchett, "Photosynthetic Pigments and Peroxidase Activity as Indicators of Heavy Metal Stress in the Gray Mangrove, Avicennia marina (Forsk) Vierh," Mar. Pollut. Bull., vol. 42, no. 3, pp. 233-240, 2001.

[6] L. Q. Ma, K. M. Komar, C. Tu, and W. A Zang, "A fern that Hyperaccumulator arsenic," Nature, p. 409:579, 2001.

[7] M. F. Y. Tam and Y. S. Wong, "Accumulation and Distribution of Heavy Metal in a Simulated Mangrove System Tread with Sawege," in Asia Pasifik Conference on Science and Managemant of Coastal Environment, 1997.

[8] W. J. Zheng, X. Y. Chen, and P. Lin, “Accumulation and biological cycling of heavy metal elements in Rhizophora stylosa mangroves in Yingluo Bay, China," Mar. Ecol. Prog. Ser., vol. 159, pp. 293301, 1997.

[9] C. L. Bini, L. Gentili, B. Maleci, and O. Vaselli, "Trace elements in plant and soils of urban parks," Annex. tocontaminated soil prost, 1995.

[10] H. S. Titah et al., "Screening and Identification of Plants at a Petroleum Contaminated Site in Malaysia For Phytoremediation," $J$. Environ. Sci. Manag., vol. 19, no. 1, pp. 27-36, 2014.

[11] A. R. A. Usman and H. M Mohamed, "Effect of microbial inoculation and EDTA on uptake and translocation of heavy metals by corn and sunflower," Chemosphare, vol. 76, pp. 893-899, 2009.

[12] B. W. Tukura, N. L. Usman, and H. B. Mohammed, "Aqua Regia and Ethylediaminetetracetic Acid (EDTA) Trace Metal Levels in Agricultural Soil," J. Environ. Chem. Ecotoxicol., vol. 5, no. 11, pp. 284-291, 2013.

[13] E. C. Peters, N. J. Gassman, J. C. Firman, R. H. Richmond, and E. A. Power, "Ecotoxicology of tropical marine ecosystems," Env. Toxicol Chem, vol. 16, pp. 12-40, 1997.

[14] M. F. Y. Tam and Y. S. Wong, "Spatial variation of heavy metals in surface sediments of Hong Kong mangrove swamps," Environ. Pollut., vol. 110, pp. 192-205, 2000.

[15] A. J. Baker and P. I. Walker, Ecophysiology of metal uptake by tolerant plants. In: Shaw, A.J. (Ed.), Heavy Metal Tolerance in Plants: Evolutionary Aspects. Florida: CRC Press, 1990.

[16] C. A. N. D'mello and G. N. Nayak, "Asessment of metal enrichment and their bioavaibility in sediment and bioaccumulation by mangrove plant pneumatophores in a tropical (Zauri), estuary, west coast of India," Mar. Polution Bull., vol. 110, pp. 221-230, 2016.

[17] S. Pakzadtoochaei and F. Einollahipeer, "Monsoon effects on Variation of heavy metals in Gwatr mangrove forests of Iran," Int. Res. J. Appl. Basic Sci., vol. 4, no. 7, pp. 1946-1952, 2013.

[18] B. Amin, E. Afriyani, and M. A. Saputra, "Distribusi Spasial Logam $\mathrm{Pb}$ dan $\mathrm{Cu}$ pada Sedimen dan Air Laut Permukaan di Perairan Tanjung Buton Kabupaten Siak Propinsi Riau," J. Teknol., vol. II, pp. 1-8, 2011. 
[19] N. T. M. Martuti, W. Budi, and Y. Bambang, "Copper Accumulation on Avicennia Marina in Tapak, Tugurejo," Waste Technol., vol. 4, no. 1, pp. 40-45, 2016.

[20] M. S. Li, Y. P. Luo, and Z. Y. Su, "Heavy metal concentrations in soils and plant accumulation in a restored manganese mineland in Guangxi, South China," Env. Pollutan, vol. 147, pp. 168-175, 2007.

[21] R. A. Wuana and F. E. Okieimen, "Heavy Metal in Contaminated Soil : A Review of Sources, Chemistry, Risk and Best Available Strategies for Remediation," Int. Sch. Res. Netwok, vol. 20, 2011.

[22] A. Nontji, Laut Nusantara. Jakarta: Djambatan, 2007.

[23] D. M. Alongi, "Movangre forests: Resilience, protection from tsunamis, and responses to global climate change," Estuar. Coast.
Shelf Sci., vol. 76, pp. 1-13, 2008.

[24] Menteri Lingkungan Hidup, "Keputusan Menteri Negara Lingkungan Hidup Nomor 51," 2004.

[25] H. P. Hutagalung and Sutomo, "Kandungan $\mathrm{Pb}, \mathrm{Cd}, \mathrm{Cu}, \mathrm{Zn}$ dalam Air, Sedimen dan Kerang Darahdi Periran Teluk Banten, Jawa Barat," Jakarta, 1996.

[26] H. Setiawan and E. Subiandono, "Konsentrasi Logam Berat pada Air dan Sedimen di Perairan Pesisir Propinsi Sulawesi Selatan," For. Rehabil. J., vol. 3, no. 1, 2015.

[27] R. J. Krupadam, R. Ahuja, and S. R. Wate, "Heavy metal binding fractions in the sedimentsof the Godavari estuary, East Coast of India," Env. Model Assess, vol. 12, pp. 145-155, 2007. 